\section{FABIANO GONTIJO}

[ORG.]

\section{(c) creative commons}

Direção editorial: Ana Kelma Gallas

Diagramação: Kleber Albuquerque Filho

Editor OMP: Eliezyo Silva

Imagem da capa: Karine Gallas

\section{ABEC}

A, ARASIL

doi) 5 crossref

\section{LESTU PUBLISHING COMPANY}

Editora, Gráfica e Consultoria Ltda

Avenida Paulista, 2300, andar Pilotis Bela Vista, São Paulo, 01310-300, Brasil.

(11)97415.4679 | editora@lestu.org | www.lestu.com.br
FICHA CATALOGRÁFICA

Dados Internacionais de Catalogação na Publicação (CIP)

\section{G641 GONTIJO, Fabiano}

Corpo, sexo, gênero: estudos em perspectiva / Fabiano Gontijo (Org.). - São Paulo, SP: Lestu Publishing Company, 2021.

\section{3 p. online}

ISBN: 978-65-996314-2-9

DOI: https://doi.org/10.51205/lestu.978-65-996314-2-9

1. Identidade de Gênero. 2. Teoria Queer. 3. Sexualidade. 4. Corpo. 5. Sociologia. I. Autor(a). II. Título. III. Lestu. IV.

CDD: 306.7

1. Gênero e sexualidade: Aspectos sociais: Sociologia: 306.7

\section{CORPO, SEXO, GÊNERO}

\section{ESTUDOS EM PERSPECTIVA}




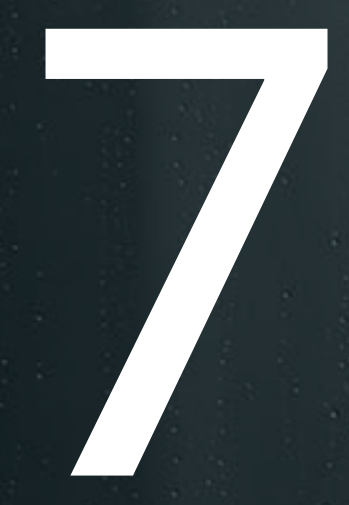




\title{
Feminicídios e intersecções: refletindo sobre o contexto do Piauí
}

\author{
Rossana Maria Marinho Albuquerque \\ João Marcelo Brasileiro de Aguiar²
}

\section{Introdução}

O texto que apresentamos aqui é resultado de um trabalho de análise sobre o fenômeno do feminicídio no Piauí, tendo como recorte as ocorrências do ano de 2020. Buscamos acompanhar as dinâmicas das ocorrências e compreender as particularidades apresentadas no estado, em um cenário marcado pela pandemia causada pela COVID-19.

Com o anúncio da emergência sanitária, a consequência mais imediata foi a adaptação das diversas atividades sociais às medidas de distanciamento demandadas para reduzir a propagação de um vírus até então desconhecido e de alta capacidade letal. No Piauí, o primeiro decreto estadual estabelecendo o distanciamento social foi publicado no dia 16 de março3.

O alerta para o aumento da violência doméstica foi anunciado pelo chefe da ONU, António Guterres, em abril de 20204, tendo em vista que a casa tem se configurado, mundialmente, como um espaço de violência contra mulheres, que poderia se agravar junto aos efeitos socioeconômicos oriundos da pandemia. No Brasil, os números de denúncias e ocorrências começaram a revelar as peculiaridades já nos primeiros dias que se

1 Doutora em Sociologia (UFSCar), professora do curso de Ciências Sociais da Universidade Federal do Piaul (UFPI), membro do quadro permanente do Programa de Pós-Graduação em Sociologia (PPGS) da mesma universidade. E-mail: rossanamarinho@ufpi.edu.br.

2 Mestrando no Programa de Pós-Graduação em Sociologia (PPGS) da Universidade Federal do Piauí (UFPI). Desenvolve pesquisa na área de violência de gênero. E-mail: joaomarcelobrasileiro@ gmail.com.

3 Decreto estadual no 18.884, de 16 de março de 2020, publicado no DOE no 50, de 16/03/2020, pag. 5-7.

4 Fonte:https://nacoesunidas.org/chefe-da-onu-alerta-para-aumento-da-violencia-domestica-em-meio-a-pandemia-do-coronavirus/. Acesso em: abril 2020. 
seguiram aos decretos estaduais de distanciamento social. As primeiras características observadas foram a queda nas quantidades de denúncias presenciais e aumento de denúncias pelos canais remotos de atendimento às mulheres (FBSP, 2020). No Piauí, entre os meses de março e abril, houve redução nos registros presenciais de ocorrências feitos nas Delegacias Especializadas de Atendimento à Mulher (DEAMs), contrastando com o aumento de 70,3\% de registros por meio do aplicativo digital "Salve Maria", em relação ao mesmo período em $2019^{5}$.

Para a construção do presente estudo, a combinação de metodologias quantitativa e qualitativa permitiu que observássemos vários aspectos do cenário de feminicídio no Piauí em 2020. Após a análise dos boletins de ocorrência e demais peças iniciais que compõem os inquéritos policiais que apuram os casos de feminicídios, identificamos particularidades ocorridas no contexto piauiense.

A análise quantitativa se deu a partir de um estudo transversal descritivo sobre o total de casos registrados no ano passado ${ }^{6}$, através da consulta às peças dos procedimentos de investigação (boletim de ocorrência e inquérito policial) produzidas no âmbito da Polícia Civil, aos microdados consolidados, bem como sua atualização ocorrida em 19 de abril de 2021. A análise descritiva considerou as seguintes variáveis: idade (faixa etária) da vítima e do autor, classificação racial da vítima (negra ou não negra) e do autor, ocupação da vítima, instrumento do crime, cidade do fato e tipo do local do fato. Os dados foram reorganizados em planilha Excel e importados para o software IBM SPSS Statistics 27, para a devida análise estatística. Os gráficos foram produzidos no Excel 365 , a partir dos resultados obtidos na análise estatística.

A parte qualitativa do estudo foi construída a partir da análise dos casos ${ }^{7}$, observando a combinação de categorias das experiências femininas, a partir de uma perspectiva feminista interseccional. Diferentemente das demais situações de violência contra as mulheres, nos casos de feminicídio não mais podemos ouvir as narrativas vivenciadas pelas próprias sujeitas, de modo que construímos a interpretação a partir dos registros de documentos, notícias e relatos de testemunhas que constroem uma versão sobre os fatos. Suas vozes, neste sentido, nos chegam por outras vias e,

5 A dinâmica apresentada pelos números nos provocou algumas indagações, que reunimos em Albuquerque e Aguiar (2020).

6 O acesso aos dados foi autorizado pela gestão da Secretaria de Segurança Pública do Piauí (SSP/ $\mathrm{PI})$.

7 Os registros de feminicídio contabilizados pela segurança pública do Piauí dão conta dos assassinatos de mulheres cis. Neste sentido, todas as experiências consideradas nesta análise se referem a este recorte de gênero. também por isso, estudar os casos de feminicídios significa lembrar do valor dessas vidas perdidas para a violência de gênero.

$\mathrm{Na}$ realidade social piauiense, no caso dos feminicídios, observamos, em um número notável de casos, que as mulheres foram assassinadas dentro das suas residências, mesmo quando não conviviam no mesmo domicílio do autor do assassinato. Embora em todos os casos se tratavam de pessoas próximas (ex-companheiros, parentes, conhecidos), a característica mais presente era a motivação do assassinato pela recusa em aceitar a autonomia das mulheres: controle obsessivo dos corpos femininos, não aceitação do fim do relacionamento ou de que a mulher pudesse vivenciar novos relacionamentos. Esse modelo de masculinidade violenta se manifestou em várias ocorrências, vitimando principalmente mulheres negras, de baixa escolaridade, com empregos de menor remuneração, em sua maioria residentes nas cidades do interior do estado.

O exame das informações contidas nos registros da segurança pública demonstra que a violência era um componente presente nas relações cotidianas vivenciadas pelas mulheres, operando como norma que buscava regular os comportamentos femininos, incidindo no espaço da residência, mesmo quando era chefiado pela mulher.

Em 2020, 31 mulheres foram vítimas da violência letal provocada pela desigualdade de gênero, vivenciada ao lado de outras desigualdades. A abordagem interseccional adotada na análise se faz fundamental, tendo em vista a necessidade de observar como as desigualdades e opressões se combinam em determinados contextos, fazendo com que algumas mulheres estejam mais vulneráveis a situações extremas de violência, ao mesmo tempo em que figuram em indicadores socioeconômicos que atestam outras vulnerabilidades.

\section{A violência de gênero em perspectiva feminista interseccional}

Ao tratar do feminicídio, estamos abordando uma modalidade de violência extrema, praticada contra mulheres, inserida como qualificadora do crime de homicídio na legislação brasileira desde 2015 (Lei 13.104/15). A criação da Lei do Feminicídio (BRASIL, 2020) foi fundamental para o enfrentamento dos assassinatos que têm nas relações desiguais de gênero sua principal motivação, permitindo a problematização de justificativas historicamente utilizadas para naturalizar a violência letal contra mulheres.

Abordar a violência de gênero passa por considerar sua dimensão histórica, cultural e relacional (BANDEIRA, 2017). O gênero é um marcador das experiências sociais, que classifica corpos, atribui significados e 
tarefas que, a depender do contexto, podem se configurar de maneira bastante desigual (CONNELL, PEARSE, 2015). O gênero é culturalmente e contextualmente produzido. Temos maneiras diversas de produzir relações de gênero, em contextos que possuem configurações específicas. Nas palavras de Schefler (2018, p. 33): "Gênero é uma categoria de análise que permite o entendimento de como a sociedade organiza modos de ser, comportamentos e define pertencimentos, revela diferenças, indica desigualdades, enfim, expressa relações de poder".

Embora o modelo binário (homem/mulher) hegemônico na cultura ocidental, fundado na anatomia física, tenha prevalecido nos contextos sociais em escala global, o modo como as relações de gênero se configuraram possuem sua historicidade e processos específicos de constituição. Para compreender o fenômeno do feminicídio considerando uma abordagem interseccional, é fundamental considerar a produção histórica da violência no contexto brasileiro, especialmente a partir do processo de colonização, que marca profundamente as hierarquias sociais, com reflexos que persistem até hoje. Neste sentido, consideramos o feminismo decolonial como uma perspectiva-chave para compreendermos a violência de gênero como um componente histórico e estrutural da sociedade brasileira. Considerando também que os processos de colonização tiveram suas particularidades internas no território brasileiro, nos interessa também pensar na história colonial piauiense como um caminho para compreender como a violência de gênero se configurou no estado (EUGÊNIO, 2014).

Maria Lugones (2014) propôs a noção de colonialidade do gênero para abordar as reiteradas hierarquias e opressões produzidas pelos processos de colonização, que subsistem mesmo quando formalmente os territórios são descolonizados. A modernidade colonial, nos termos da autora, hierarquizou os indivíduos como humanos/não humanos, segundo os interesses coloniais, de modo a desumanizar e racializar as populações nativas dos territórios colonizados, bem como as populações trazidas à força para fins de trabalho escravo. Tais processos se constituíram mediante o emprego de várias violências, que descaracterizaram culturas, violentaram corpos, exterminaram povos e modos de vida, impondo o modelo do colonizador como parâmetro de condição humana. Para Lugones (2014), o gênero é compreendido como uma categoria introduzida no processo de colonização, parte constituinte dos empreendimentos coloniais e da produção de hierarquias a eles subjacentes.

Pensando na chave do feminismo decolonial, olhamos para as desigualdades de gênero da atualidade considerando sua relação com a formação social histórica: como nos tornamos um país profundamente violento do ponto de vista racial, de gênero, orientação sexual? Os números que nos informam atualmente sobre violências e letalidade comunicam também sobre quais corpos historicamente foram mais subalternizados e aos quais foi negada sua condição de humanidade. A categoria gênero, neste sentido, foi produzida em combinação com demais hierarquias, fazendo com que alguns corpos estejam mais passíveis de opressões que outros.

Feitas as considerações anteriores, é preciso pensar nas realidades complexas vivenciadas pela categoria denominada "mulheres". Tornar-se mulher é um processo sociocultural e o modo como se vivencia a condição feminina é acompanhado de outras categorias. Estudar o feminicídio nesta perspectiva significa identificar, para além das quantificações, quais mulheres estão morrendo mais e em quais condições sócio-históricas vivem. A sociedade brasileira, em sua formação histórica, teve o patriarcado como um dos seus pilares de dominação política e na violência contra corpos um instrumento de controle (SAFFIOTI, 2015). Os ecos dessa formação social se manifestam, ainda hoje, nas violências produzidas contra povos indígenas, população LGBTQIA+, população negra, mulheres cis, considerando também que um mesmo indivíduo pode viver situações combinadas de violência, em virtude dos marcadores envolvidos na sua experiência.

Se o feminismo decolonial nos permite pensar os fenômenos atuais em sua relação com os processos de colonização, a perspectiva interseccional contribui para a interpretação dos indicadores combinados de desigualdades e opressões conforme se manifestam no presente, destacando a relevância de perceber os limites de analisar isoladamente as categorias, seja o gênero, a raça, a classe social, orientação sexual, a geração, dentre outros. As categorias se combinam relacionalmente, o que significa que é preciso observar como elas estão associadas nos contextos específicos, bem como são produzidas em cada contexto, evitando noções apriorísticas ou uma estrutura fixa para interpretar realidades sociais (COLLINS, BILGE, 2021). Uma perspectiva interseccional crítica, neste sentido, toma as categorias como analíticas e não simplesmente descritivas, considerando sua relacionalidade (COLLINS, BILGE, 2021). Deste modo, se observamos que mais mulheres negras estão sendo assassinadas, as categorias gênero e raça não são apenas descritivas destas experiências; a partir de uma abordagem interseccional crítica, interessa compreender como esses corpos foram generificados e racializados - ou o que resulta dessa combinação -, de modo a se tornarem mais passíveis de serem violentados. Quando indagamos sobre quais mulheres foram 
vítimas de feminicídio, estamos buscando compreender suas experiências e como a violência de gênero entrou nos seus roteiros de vida e morte.

Tendo esses pressupostos em mente, pensamos na realidade piauiense, de modo a compreender como essas vidas entraram para as estatísticas da violência letal e quais marcadores, para além do gênero, faziam parte das suas vivências. Os estudos de Villa (2020) têm contribuído para a análise do feminicídio no Piauí, considerando também os elementos de colonialidade na forma como os corpos têm sido alvo da violência letal. A autora analisa o feminicídio a partir do dispositivo da colonialidade que, em seus termos, tem como finalidade

...servir como ferramenta teórica crítica na busca por respostas para tudo quanto foi perdido, especialmente pela escravidão e pelo confisco das tradições dos povos através da irrupção de políticas de controle de vidas por elas impostas e vigentes até a atualidade com inovações morfológicas processualmente adequadas historicamente aos contextos vivenciados (VILLA, 2020, p. 54)

A análise de Villa, a partir do dispositivo da colonialidade, nos convida a observar, na realidade piauiense, como os corpos femininos foram/são territorializados e colonizados e, neste sentido, mais sujeitos às violências. $\mathrm{Na}$ proposição da autora, a ferramenta do dispositivo da colonialidade se desdobra em três categorias (VILLA, 2020, p. 64), que nos permitem verificar as estratégias e formas de controle dos corpos, as modalidades de violência empregada e para quem os atos violentos são dirigidos na maioria dos casos: mandato da masculinidade, precariedade e gestos simbólicos. Mais uma vez, em suas palavras:

O Feminicídio corresponde a processo de colonização porque envolve captura, territorialização e desfazimento do corpo colonizado, em outros termos, trata-se do exercício de poder que retira componentes como liberdade, dignidade e vida, tal como se dera por ocasião do processo de colonização das terras brasileiras, daí a adequação não só do termo, mas do significado de colonização à temática do estudo. A acepção é de que a categoria gênero, tomada como categoria de análise decolonial, molda o Dispositivo da Colonialidade e traz como efeitos Gestos Simbólicos, Precariedade e Mandato da Masculinidade (VILLA, 2020, p. 64).
Na formação social piauiense, marcada pela colonização fundada na grande propriedade rural, a violência atuou como um componente de poder de modo que encontramos nos estudos sobre o período colonial várias menções às violências praticadas contra povos nativos, pessoas escravizadas, mecanismos de formação de arranjos conjugais baseados na raptura de mulheres, além dos registros de atos de resistência de indivíduos ou grupos que buscavam maneiras de enfrentar os processos brutais de desumanização aos quais estavam submetidos (BRANDÃO, 2011).

Pensar nos feminicídios na atualidade, a partir das chaves da colonialidade e interseccionalidade, significa compreender os fenômenos tais como se apresentam como violências do presente, mantendo as indagações sobre quais processos fizeram da violência um componente da nossa realidade, muitos deles silenciados historicamente ou desconhecidos em virtude do apagamento da memória social.

\section{Relações de poder e violência letal contra mulheres}

O espaço da casa tem se constituído como cenário de relações de poder e práticas de violências contra as mulheres. Nos últimos anos, foi verificado no Brasil o aumento dos assassinatos de mulheres no ambiente doméstico. O ambiente da casa, neste sentido, se expressa como um cenário no qual se manifestam relações e desigualdades de gênero, que estão presentes de várias formas.

Existe uma diferenciação espacial da violência exercida sobre o corpo feminino, esteja ele no ambiente público ou privado. É bom pontuar, no entanto, que o ambiente doméstico é onde a mulher mais sofre violências, sobretudo uma vez que os dados mostram que as agressões vêm em geral de seus companheiros (SANTOS, 2020, p. 68).

Tratamos, então, o espaço da casa não somente como moradia ou espaço físico onde estão localizados os sujeitos (MILANI, 2020); o espaço é pensado como constituinte das relações sociais generificadas, que fazem com que na sociedade brasileira - ou piauiense - não seja um local seguro para as mulheres, especialmente as negras.

De acordo com o Atlas da Violência 2020 (IPEA, 2020), no período compreendido entre 2008-2018, o Brasil apresentou um aumento de 4,2\% nos homicídios de mulheres. O Piauí, mesmo estando entre os estados com menores taxas de homicídios de mulheres, registrou um aumento de $30,6 \%$ no referido decênio. Na década analisada, a observação de gênero e raça 
mostrou que entre as mulheres não negras houve diminuição no número de homicídios de $11,7 \%$, no Brasil e, entre as mulheres negras, um aumento de $12,4 \%$. O Piauí apresentou redução de $16,7 \%$ de homicídios de mulheres não negras e aumento de $38,7 \%$ no caso das mulheres negras, muito acima do percentual nacional.

No que se refere ao local dos assassinatos de mulheres, o Atlas da Violência indica haver duas tendências observadas no Brasil nos últimos anos: aumento dos casos na residência das vítimas e diminuição fora das casas. Segundo o relatório (IPEA, 2020, p. 39), “...entre 2013 e 2018, ao mesmo tempo em que a taxa de homicídio de mulheres fora de casa diminuiu $11,5 \%$, as mortes dentro de casa aumentaram $8,3 \%$, o que é um indicativo do crescimento de feminicídios".

Em relação aos feminicídios, o Anuário da Violência 2020 (FBSP, 2020) indicou que entre os anos 2018-2019 o Brasil registrou aumento de $7,1 \%$ dos feminicídios e uma proporção de 35,5\% em relação ao número total de assassinatos de mulheres.

O Piauí apresentou percentuais acima da média nacional: aumento de $11,2 \%$ dos casos de feminicídio (2018-2019) e proporção de $63 \%$ de feminicídios em relação ao número total de homicídio de mulheres, 2a posição no país, perdendo apenas para o Amapá, que apresentou proporção de 63,6\%. O Anuário apresenta um perfil predominante, nos casos de feminicídios, que também se manifestam no Piauí: arma branca como principal instrumento utilizado, residência como local predominante do assassinato, companheiro/ex-companheiro como autor dos assassinatos na maioria dos casos, maioria de mulheres negras e pobres entre as vítimas.

Gráfico 01 - Frequência absoluta mensal de feminicídios no Piauí (2020)

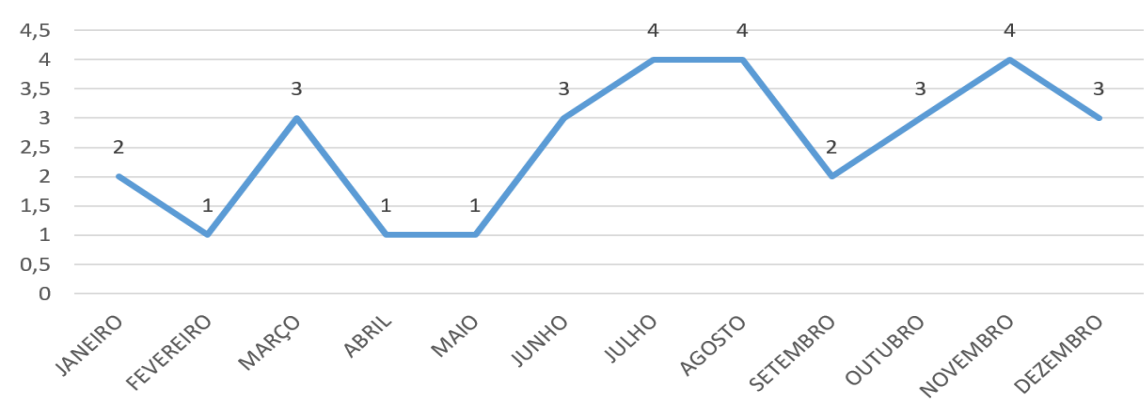

Fonte: Elaboração dos/as autores/as, com base nos dados disponibilizados pela SSP/PI
Segundo dados da SSP/PI, no ano de 2020, 62 mulheres foram vítimas de mortes violentas intencionais (MVI), dentre estas 31 de feminicídio, representando um aumento de 6,89\% em relação a 2019, e revelando um recorde histórico desde $2016^{8}$. A proporção de feminicídio em relação às $\mathrm{MVI}$ de mulheres em 2020 manteve-se em 50\%, índice abaixo do ano de 2019 (63\%) e igual ao de 2018 (50\%), revelando que no Piauí a causa preponderante de assassinatos de mulheres é o feminicídio.

Em 2020, o Piauí registrou uma média mensal de 2,6 feminicídios. Os meses que mais registraram casos foram julho, agosto e novembro: 4 vítimas em cada mês. Do total de casos, 26 foram registrados após o início do distanciamento social no Piauí (Gráfico 01). A maioria dos casos de feminicídio no ano de 2020 ocorreu no interior do estado (25 vítimas). Observando o recorte racial e a faixa etária da vítima de feminicídio em 2020, nota-se que mais de $80 \%$ eram negras, 32,2\% tinham entre 20 e 29 anos e a idade média da vítima é 37 anos. A partir da análise bivariada, é possível indicar que a maior incidência deste crime se deu, em 2020, entre as mulheres negras e na faixa etária de 20 e 34 anos de idade, que representaram $35,5 \%$ das vítimas (Tabela 01 ). Um elemento notáve é a presença das mulheres negras vítimas de feminicídio em todas as faixas etárias, em contraste com as não negras, demonstrando graus de vulnerabilidade quando cruzamos raça, gênero e faixa etária.

Tabela 01 - Tabela de referência cruzada raça e faixa etária das vítimas de feminicídio em 2020

\begin{tabular}{cccc} 
Faixa etária /Raça & não negra & negra & Total por faixa etária \\
\hline 15 a 19 & 0 & 3 & 3 \\
20 a 24 & 1 & 4 & 5 \\
25 a 29 & 1 & 4 & 5 \\
30 a 34 & 0 & 3 & 3 \\
35 a 39 & 2 & 2 & 4 \\
45 a 49 & 2 & 2 & 4 \\
50 a 54 & 0 & 3 & 3 \\
55 a 59 & 0 & 1 & 1 \\
60 ou mais & 0 & 3 & 3 \\
\hline Total Raça & 6 & 25 & 31 \\
\hline
\end{tabular}

Fonte: Elaboração dos/as autores/as, com base nos dados disponibilizados pela SSP/PI

8 Dados da Secretaria de Segurança Pública do Piauí disponíveis no site <www.ssp.pi.gov.br/estatisticas>. Acesso em 1으 de maio de 2021. 
Analisando o instrumento utilizado para a consumação do feminicídio, observa-se uma dinâmica distinta do total das MVI no Piauí" pois, segundo os dados disponíveis, $62,34 \%$ dos assassinatos no Piauí em 2020 tiveram a participação da arma de fogo; porém, no caso dos feminicídios, o instrumento prevalecente é a arma branca, utilizada em aproximadamente $55 \%$ dos casos.

Observando o tipo de instrumento utilizado para o assassinato e o recorte racial da vítima identificamos que, entre as mulheres negras, houve uma maior variação de instrumentos, em comparação com as mulheres não negras. As mulheres negras foram mais vitimadas em todos os tipos de instrumentos utilizados, incluindo a categoria "Outros", que corresponde a pedaço de madeira, estrangulamento, demais objetos contundentes (TABELA 02).

Quando nos remetemos a uma abordagem interseccional da violência, observamos que a experiência racializada do gênero torna o corpo mais suscetível não somente à letalidade, mas a formas mais intensas de desfiguração, elemento que demonstra a necessidade de se verificar como as categorias se combinam nas experiências práticas das mulheres e elaborar mecanismos de proteção das suas vidas que efetivamente acessem as assimetrias e graus de vulnerabilidade.

Tabela 2: Tabela de referência cruzada raça e instrumento empregado em 2020

\begin{tabular}{lcccccccc}
\hline \multicolumn{1}{c}{ Raça } & \multicolumn{2}{c}{ Arma branca } & \multicolumn{2}{c}{ Arma de fogo } & \multicolumn{2}{c}{ Outros } & \multicolumn{2}{c}{ Total } \\
& $\mathrm{N}$ & $\%$ & $\mathrm{~N}$ & $\%$ & $\mathrm{~N}$ & $\%$ & $\mathrm{~N}$ & $\%$ \\
Negra & 14 & 82,4 & 7 & 77,8 & 4 & 80 & 25 & 80,6 \\
Não negra & 3 & 17,6 & 2 & 22,2 & 1 & 20 & 6 & 19,4 \\
\hline Total & 17 & 100 & 9 & 100 & 5 & 100 & 31 & 100 \\
\hline
\end{tabular}

Fonte: Tabela elaborada pelos/as autores/as, com base nos dados disponibilizados pela SSP/P

Analisamos as variáveis faixa etária e raça do autor do feminicídio. No estudo etário ${ }^{10}$, a maioria possuía entre 30 e 44 anos de idade (52\%), permanecendo a idade média em aproximadamente 39 anos (GRAFICO 02). Quanto à classificação racial ${ }^{11}$, o estudo revelou que aproximadamente $82 \%$ dos autores dos feminicídios eram negros.

9 Relatório Provisório de Criminalidade 2020 da SSPPI, disponível em <http://www.ssp.pi.gov.br/ download/202105/SSP06 b680593a44 pdf>, acessado em 1을 de maio de 2021.

10 Os registros sem idade, foram desconsiderados para a análise.

11 Os registros sem cor da pele foram desconsiderados para a análise.
Gráfico 02 - Frequência relativa da faixa etária dos autores do feminicídio (2020)

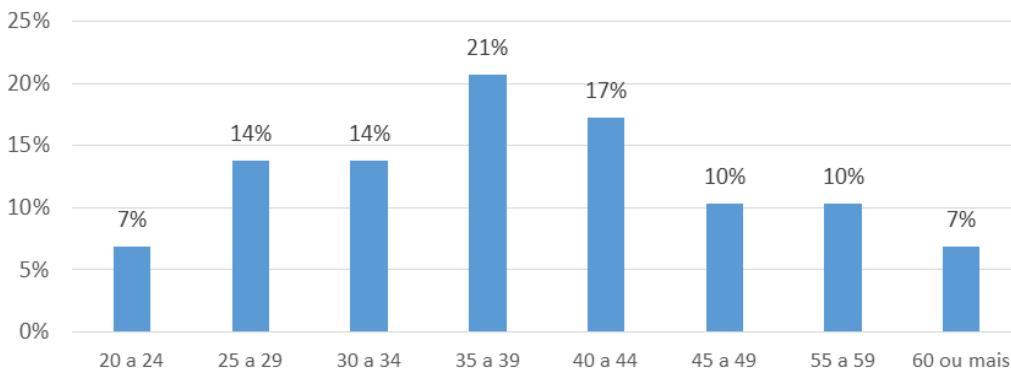

Fonte: Tabela elaborada pelos/as autores/as, com base nos dados disponibilizados pela SSP/PI

A residência foi o local preponderante do feminicídio em 2020 representando aproximadamente $74 \%$ dos casos registrados (Gráfico 03 ), acompanhando o perfil registrado nos anos anteriores no estado e dos dados registrados no cenário nacional. Com uma pequena variação no percentual, a residência prevalece como local do crime, tanto na capital $(83,3 \%)$, quando no interior $(72 \%)$.

Gráfico 03 - Frequência relativa de feminicídios por local do fato (2020)

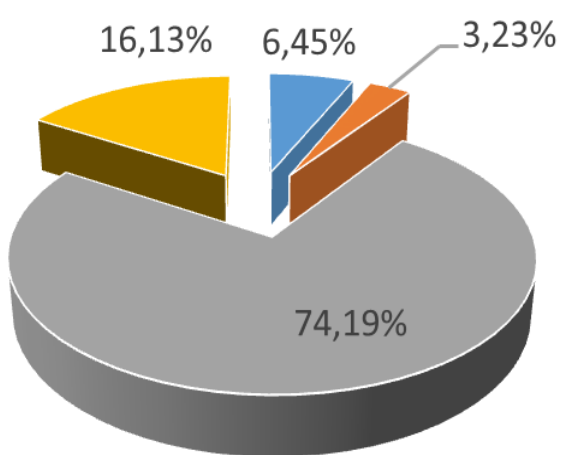

- Área Rural " estabelecimento comercial " Residência " Via Pública

Fonte: Elaboração dos/as autores/as, com base nos dados disponibilizados pela SSP/PI

Procuramos observar também se o autor do assassinato coabitava no mesmo domicílio da vítima, com o intuito de observar o aspecto da convivência durante a pandemia e facilidade de acesso ao local de moradia. Os registros dos documentos analisados no banco de dados da segurança pública não oferecem precisão com relação a esta informação. 
Porém, fazendo o mapeamento a partir das informações contidas nos registros iniciais das investigações, foi possível identificar o aspecto "coabitação" em 18 casos. Entre estes, identificados que, em $67 \%$ das situações, o autor não coabitava no mesmo domicílio da vítima, embora fosse pessoa conhecida ou tivesse algum vínculo de proximidade. Este dado é importante, para refletirmos sobre as relações de poder e práticas de violência contra as mulheres existentes no espaço da casa, que representa um local de insegurança, para além da convivência imediata com os autores de violência. Neste sentido, poderíamos dizer que esta foi mais uma das faces da violência no contexto da pandemia, ampliando a narrativa sobre a violência necessariamente associada às situações de convivência e confinamento.

\section{Cenários e contextos das mortes: uma abordagem interseccional}

Relatar os casos de feminicídios é se referir às vidas que foram interrompidas de forma violenta, às aspirações, sonhos, desejos, projetos, que se foram junto com as mulheres. Escrever sobre as mortes é conciliar a tarefa de estudar sociologicamente o feminicídio, tão recorrente na realidade piauiense, e de lembrar da importância das vidas perdidas para a violência de gênero. Nos 31 casos ocorridos em 2020, várias histórias de mulheres, na capital e nas cidades do interior, vivenciando o gênero junto a outros marcadores sociais. Na presente seção, tentamos nos aproximar dos cenários e contextos dos feminicídios, observando como as categorias se combinaram em diferentes situações, tornando algumas vidas mais passíveis de letalidade.

Conforme já mencionado, a maioria das vítimas foram as mulheres negras, pobres e de baixa escolaridade. A motivação mais frequente era o controle excessivo sobre os corpos femininos, seja na forma do sentimento de posse, na recusa em aceitar o término de um relacionamento ou que a mulher vivenciasse um novo relacionamento afetivo. Nestas situações, observamos como o gênero se combinava com uma sexualidade normativa, que se expressava em práticas violentas e controles dos corpos femininos. Viver o gênero neste modelo de arranjo afetivo significava adentrar em um roteiro autoritário difícil de sair. Em alguns casos, as mulheres sequer demonstravam interesse e, ainda assim, foram alvo da violência machista.

Com frequência, as ameaças de morte exerciam um controle muito forte nas decisões das mulheres sobre deixar o relacionamento ou acionar mecanismos institucionais de denúncias. A violência operava como norma, também conhecida pelas demais pessoas do convívio das mulheres, como foi identificado nos relatos de testemunhas. Mesmo que as mulheres não estivessem sozinhas ou contassem com redes de apoio pessoais, as práticas machistas exerciam grande influência. A verbalização do assassinato aparece em vários casos, seja na forma de ameaça ou como ato que precede a consumação. Este aspecto se mostra relevante, porque indica a força enunciativa do vocabulário violento e que conviver com a ameaça de morte se constitui como um risco real para as mulheres.

A heterogeneidade de situações revelava que várias mulheres estavam assumindo protagonismos em suas vidas (chefiavam famílias, vivenciavam novas experiências afetivas) e foram alvo da violência letal por não se ajustarem ao roteiro normativo imposto pelas masculinidades violentas. O cenário predominante foi a residência da vítima, independente de coabitar com o autor do assassinato. Além do ambiente doméstico como cenário prevalecente, a ocorrência de feminicídios em outros locais mostrava que a violência de gênero torna qualquer lugar inseguro para as mulheres. A partir de agora, discorremos sobre alguns casos, agrupando em eixos conforme aspectos observados nas experiências:

a) Raça e classe social - dois casos de feminicídio aqui situam os extremos das experiências femininas: $M 2^{12}$ - uma mulher branca ${ }^{13}$, a única com ensino superior dentre as vítimas, médica, residente na capital do estado; M9 - uma mulher preta, ensino fundamental incompleto, morava em uma cidade do interior e morreu no dia em que recebeu a parcela do auxílio emergencial. Ambas foram assassinadas em suas casas, com arma branca. Suas realidades sociais, no entanto, eram bastante distintas. M2 morreu no mês de abril, na capital, na fase mais intensa do distanciamento social, e não coabitava com o autor do assassinato. Morava em um condomínio de apartamentos e foi assassinada pelo ex-companheiro - homem branco, 35 anos -, com quem tinha uma filha criança, que presenciou a cena do crime. $\mathrm{O}$ autor do assassinato conseguiu adentrar no condomínio, arrombou a porta da residência da vítima e consumou o crime com várias perfurações de faca, na cozinha da casa. Constava nos registros que M2 estava iniciando um novo relacionamento dias antes do assassinato. O autor acabou falecendo, horas depois, em um acidente de trânsito. O caso de M9 foi bastante emblemático. Mulher preta, 28 anos, era do lar. No mês de maio,

12 As identidades das mulheres serão protegidas, sendo mencionadas pela letra " $M$ ", seguida de um número.

13 Nas seções anteriores, utilizamos "classificação racial" na análise estatística, como forma de demarcar os aspectos culturais e políticos do termo. Onde consta o termo mulheres negras, agregamos pretas e pardas. Nesta seção, utilizaremos a categoria "cor da pele", conforme os dados da segurança pública, reproduzindo os registros que caracterizavam as vítimas. 
tinha recebido o auxílio emergencial ${ }^{14}$ de $\mathrm{R} \$$ 600,00 (seiscentos reais) e comprou alimentos para uma refeição que compartilhou com parentes e pessoas próximas. Coabitava com o companheiro, 24 anos, diarista, autor do assassinato. Uma faca que horas antes era utilizada na refeição, virou arma branca que tirou sua vida. Nos registros policiais, o incômodo do companheiro com a realização do "churrasco", a desconfiança sobre M9 estar envolvida afetivamente com outra pessoa, as tensões e ameaças aumentando ao longo da noite, culminando no feminicídio. Embora convivesse com o autor do assassinato, os relatos indicam a agência de M9 no espaço da casa, inclusive sua postura altiva diante do conflito que precedeu sua morte. Nos depoimentos, testemunhas mencionam o comportamento "ciumento" do autor, demonstrando que a violência era presente no cotidiano do casal. M9 talvez seja a representação mais característica da combinação de vulnerabilidades no contexto da pandemia.

b) Gênero, raça e geração: as mulheres negras foram assassinadas em todas as faixas etárias analisadas e aqui chamou atenção a semelhança da motivação do assassinato de duas mulheres pardas, com diferentes idades. Nos dois casos, os autores dos assassinatos não eram correspondidos em seus interesses pelas mulheres. M1 tinha 15 anos, parda, estudante, morava no interior do estado. Foi assassinada pela manhã, no mês de junho, com golpes de machado na cabeça, enquanto dormia, por um conhecido da família que adentrou a residência. Segundo consta nos registros, o autor tinha "desejo sexual" pela adolescente e não era correspondido. Era um homem pardo, 37 anos, escolaridade e ocupação não registrados. Após cometer o feminicídio, o autor se matou. M15 tinha 54 anos, era parda, do lar, morava no interior. Foi vítima de arma de fogo e seu corpo foi encontrado em uma estrada. Os relatos das testemunhas mencionavam as constantes perseguições do autor do assassinato à M15 e que houve até mesmo tentativa de estupro, dias antes do feminicídio. Nos registros, as menções aos aspectos geracionais, que M15 era "uma senhora de respeito", que era "uma senhora de idade" que não devia ser importunada pelo homem que insistia em ter um relacionamento.

c) gênero e o potencial letal das ameaças: em vários casos, a presença da ameaça se constituía como um forte componente de controle das mulheres e risco real de letalidade. M12 morreu no mês de junho, no interior do estado, vítima de arma fogo (espingarda caseira). Tinha 32 anos, parda, do lar, vivia em união estável, em um relacionamento afetivo conturbado, iniciado desde a sua adolescência. Sua convivência

14 Benefício instituído pela Lei 13.982/2020, que foi fundamental para as pessoas mais impactadas economicamente pela pandemia. com o autor do assassinato - 35 anos, pardo, lavrador - era permeada de tensões, ameaças, agressões, que são narradas pelas testemunhas ouvidas no caso. Dias antes do ocorrido, M12 questionou o comportamento do companheiro, que desfrutava de liberdade e da companhia de outras mulheres, enquanto tentava controlar ao máximo a autonomia dela. As ameaças de morte são descritas pelas testemunhas como o motivo da permanência da vítima na situação de violência. Há relatos de que os familiares fizeram várias tentativas de interferir nas situações de violência e convencê-la a deixá-lo, mas todas foram insuficientes. O fato de que as iniciativas familiares de proteger a vida de M12 se revelaram insuficientes demonstra a necessidade de mecanismos institucionais de proteção da vida das mulheres que consigam acessar, efetivamente, seus cotidianos, evitando o extremo da letalidade.

d) a recusa da autonomia feminina: M4 tinha 56 anos, parda, ensino fundamental incompleto, do lar, residente no interior do estado. O feminicídio ocorreu em dezembro, na sua casa, juntamente com mais 2 mortes: o atual companheiro e o ex. M4 estava prestando cuidados ao ex, que passou em residir em sua casa, por conta de uma depressão, agravada pelo recente desemprego. Tratava-se de um homem pardo, 61 anos, de escolaridade não informada. Fazia pouco tempo que M4 estava em um novo relacionamento. Na mesma noite, o ex matou o casal e também se matou, na residência da vítima. M6 era uma mulher branca, 45 anos, agente de saúde, morava no interior do estado. Não coabitava com o autor do feminicídio e, ainda assim, foi assassinada em sua residência. Durante anos foi casada, mas se queixava que o esposo passava muito tempo longe e se relacionava com outras mulheres. Se sentia sozinha, segundo os relatos, e resolveu deixar o relacionamento. $\mathrm{O}$ ex era um homem pardo, pedreiro, 49 anos. Ela estava com um novo companheiro, tendo apoio dos familiares na decisão. Foi assassinada pelo ex, com arma de fogo. O autor adentrou a residência da vítima sem ser visto e praticou o feminicídio. $\mathrm{O}$ caso de M6 revela uma situação extrema de tentativa de controle sobre as livres escolhas da mulher, tendo em vista que o autor estava residindo em outro estado e se deslocou até o Piauí para cometer o feminicídio.

e) as denúncias que não evitaram as mortes: em alguns casos, havia relatos de denúncias prévias de violências. M13 vivia na capital, tinha 20 anos, era uma mulher preta e trabalhava como vendedora. No mês e março, se dirigiu à casa do ex-companheiro, para visitar o filho. Foi violentada com um pedaço de madeira, teve várias lesões corporais e foi internada em um hospital, onde faleceu dias depois. M13 vivenciou violências, recebia ameaças do ex e chegou a registrar boletins de ocorrência. M14 tinha 
decidido terminar o relacionamento e chegou a fazer uma denúncia em delegacia no interior do estado, no mês de novembro. Foi assassinada no mesmo dia em que fez a denúncia, com arma branca, na via pública. Os registros dão conta de que sua filha gritava e chorava, pedindo socorro. Era uma mulher parda, de 49 anos, do lar, ensino fundamental incompleto. 0 autor era o ex - homem preto, 38 anos, ensino fundamental incompleto, churrasqueiro. M7 foi morta na porta da sua residência, no mês de outubro, na capital. Estava entre a casa e a rua, mediando uma situação, na qual participava como avó e mãe. M7 tinha 52 anos, parda, autônoma e foi morta por arma de fogo. Seu ex-genro tinha 35 anos ${ }^{15}$, cumpria medida protetiva de urgência e estava impedido de se aproximar da filha dela. Naquele dia, o ex-genro havia combinado de levar os filhos de volta, na residência de $\mathrm{M7}$. O autor do assassinato era descrito como violento em todos os relacionamentos afetivos anteriores e a filha de M7 também tinha vivenciado situações de violência, razão pela qual buscava se proteger e tinha como vínculo apenas os filhos oriundos do antigo relacionamento. $A$ vítima não tinha vínculo direto com o autor, porém a "morte em razão do gênero" se associa à sua posição de avó na referida circunstância. A morte de M7 demonstra a importância da necessidade de ampla proteção, seja da mulher que denuncia a violência, quanto de seus familiares.

\section{Considerações finais}

Na presente análise, caracterizamos o cenário dos feminicídios no estado do Piauí, a partir de uma abordagem que combinou dimensões quantitativas e qualitativas do fenômeno. A observação desta realidade revelou que as mulheres negras estiveram mais vulneráveis à letalidade. A maior parte das mulheres, entre negras e não negras, vivenciavam outros aspectos de desigualdades sociais, a exemplo de ocupação/renda, escolaridade, que potencializaram suas vulnerabilidades.

Quando observamos o perfil dos autores dos assassinatos, também verificamos que são homens que experienciam desigualdades sociais, sendo maioria negros, de baixa escolaridade e ocupações de menor remuneração. Se, do ponto de vista da classe social, essas experiências parecem se aproximar, do ponto de vista do gênero a assimetria é visível. A maneira como os autores dos assassinatos tratavam as mulheres, como suas propriedades, parecia ser a certeza de que eram senhores de algo, de que sua autoridade era capaz de controlar as vidas e corpos femininos. As desigualdades sociais se combinam com as de gênero e tornam a vida

15 Não constavam informações sobre cor da pele, escolaridade e ocupação. das mulheres mais precárias. Enfrentar o cenário de letalidade também demanda que observemos como se produziram as masculinidades violentas entre homens que também vivenciam desigualdades em suas vidas.

A letalidade teve a marca da violência de gênero, mas antes de entrar para essa trágica estatística, a perspectiva de uma vida com possibilidades de autorrealização "morria" lentamente, cada vez que as mulheres deixaram de ter acesso aos recursos materiais e simbólicos produzidos socialmente, inclusive aos mecanismos que pudesse efetivamente proteger essas vidas e mudar o roteiro de violências do cotidiano.

As práticas de violência estavam presentes nos cotidianos das mulheres, sendo de conhecimento das pessoas do convívio ou de lugares que elas frequentavam. O fato de que as redes de apoio pessoais se mostravam insuficientes para barrar as práticas de violência parece indicar a necessidade de elaboração de mecanismos institucionais de proteção das vidas das mulheres que cheguem em seus cotidianos e sejam percebidos por elas como pontos de apoio que as fortaleçam, antes do quadro de violência se agravar. Para além da proteção contra a violência, que as mulheres possam acessar outros direitos, que ampliem sua margem de escolhas ao longo da vida e os horizontes de uma vida vivível com liberdade e segurança.

A abordagem interseccional nos permitiu observar que, embora o marcador de gênero tenha um peso fundamental neste tipo de letalidade, a condição feminina é vivenciada juntamente com outros marcadores, que tornam alguns corpos mais passíveis de violência e letalidade que outros. Neste sentido, enfrentar o fenômeno do feminicídio a partir desta perspectiva, significa compreender como a violência se entrelaça nos contextos vivenciados pelas mulheres, de modo a observar os mecanismos que aumentam a vulnerabilidade e riscos de letalidade. Compreender as especificidades dos contextos pode auxiliar nesse longo caminho de enfrentamento das desigualdades e opressões, promovendo os direitos, autonomia e segurança para as mulheres.

\section{Referências}

BANDEIRA, Lourdes Maria. Violência, gênero e poder: múltiplas faces. In Mulheres e violências: interseccionalidades / Organização Cristina Stevens, Susane Oliveira, Valeska Zanello, Edlene Silva, Cristiane Portela, Brasília, DF Technopolitik, 2017.

BRANDÃO, Tanya Maria Pires. Rapto de Mulheres: estratégia na formação de núcleos familiares, capitania do Piauí, Século XVIII. In: CLIO - REVISTA DE PESQUISA HISTÓRICA, n. 29.2 ISBN 0102-9487, 2011. 
BRASIL. Presidência da República. Lei no 13.104, de 9 de março de 2015. Disponível em: http://www.planalto.gov.br/ccivil_03/_ato20152018/2015/Lei/L13104.htm>. Acesso em: 20 abr. 2020.

COLLINS, Patricia Hill, BILGE, Sirma. Interseccionalidade. São Paulo: Boitempo, 2021.

CONNELL, Raewyn; PEARSE, Rebecca. Gênero: uma perspectiva global. São Paulo: nVersos, 2015.

EUGÊNIO, João Kennedy Eugênio (org). Escravidão Negra no Piauí e temas conexos. Teresina: EDUFPI, 2014.

FÓRUM BRASILEIRO DE SEGURANÇA PÚBLICA (FBSP). Anuário Brasileiro de Segurança Pública. Ano 14, 2020. ISSN 1983-7364.

INSTITUTO DE PESQUISA ECONÔMICA APLICADA (IPEA). Atlas da Violência, 2020. Disponível em: https://www.ipea.gov.br/atlasviolencia/ download/24/atlas-da-violencia-2020. Acesso em: 15 abr. 2021.

LUGONES, María. Rumo a um feminismo descolonial. Estudos Feministas, Florianópolis, 22(3): 320, setembro-dezembro/2014

MILANI, Patricia Helena, LIMA, Bianca de Oliveira. A Geografia e a Violência de Gênero: Um Olhar a partir de Três Lagoas - MS. Revista Latino Americana de Geografia e Gênero, v. 11, n. 1, p. 77 97, 2020. ISSN 21772886.

SAFFIOTI, Heleieth. Gênero, patriarcado violência. São Paulo: Expressão Popular: Fundação Perseu Abramo, 2015.

SCHEFLER, Maria de Lourdes Novaes. Território e gênero: territorialidades ausentes. In: Territorialidades: dimensões de gênero, desenvolvimento e empoderamento das mulheres / Cristiano Rodrigues ... [et al.] (org.). Salvador: EDUFBA, 2018.

VILLA, Eugênia Nogueira do Rêgo Monteiro. Circuito do Feminicídio: silêncio murado do assassinato de mulheres. Rio de Janeiro: Lumen Juris, 2020. 